\title{
Integrating corpus work into secondary education: From data-driven learning to needs-driven corpora
}

\author{
SABINE BRAUN \\ Centre for Translation Studies, Department of Languages and Translation Studies, \\ University of Surrey, Guildford GU2 7XH, UK \\ (email:S.Braun@surrey.ac.uk)
}

\begin{abstract}
This paper reports on an empirical case study conducted to investigate the overall conditions and challenges of integrating corpus materials and corpus-based learning activities into Englishlanguage classes at a secondary school in Germany. Starting from the observation that in spite of the large amount of research into corpus-based language learning, hands-on work with corpora has remained an exception in secondary schools, the paper starts by outlining a set of pedagogical requirements for corpus integration and the approach which has formed the basis for designing the case study. Then the findings of the study are reported and discussed. As a result of the methodological challenges identified in the study, the author argues for a move from 'data-driven learning' to needs-driven corpora, corpus activities and corpus methodologies.
\end{abstract}

Keywords: corpus-based language learning, corpus integration, pedagogically relevant corpora

\section{Introduction}

Since Tim Johns' $(1986,1991)$ pioneering suggestions for the use of corpora in language learning, the potential of corpora for language pedagogy has been widely acknowledged, and research into this field has been broadening steadily (see Braun, Kohn \& Mukherjee, 2006 for a recent collection of research papers). Empirical work, however, has been largely confined to tertiary education (see Chambers, 2007, for a recent overview).

In a rare empirical study focussing on secondary education, Rohrbach (2003) used a small English corpus of tourist brochures to make his German students aware of characteristic discourse moves and to let them study the means of expression typically associated with these moves. Apart from this, a number of suggestions for corpus-based work in school has been made (e.g. Braun \& Chambers, 2006; Mukherjee, 2002, 2004; 
Siepmann, 2006; Wüsthoff \& Rüschoff, 2000 and the ICT4LT website), drawing on materials from a variety of corpora, and Kaltenböck and Mehlmauer-Larcher (2005) considered the potential and limitations of using the British component of the Corpus of International English (ICE) in secondary school.

While the overall absence of corpus work in secondary school might seem overwhelming in view of the large amount of research into corpus-based language learning, a number of reasons can be identified to explain this situation. One of them is, for the time being at least, the situation in teacher training. McEnery and Wilson (1997a) and Chambers (2007) have emphasised that the integration of corpus studies into preservice teacher training is in itself a very recent development. Relevant initiatives are only just beginning to emerge (e.g. Amador Moreno, Chambers \& O'Riordan, 2006; Davies \& Russell-Pinson, 2004). It will therefore at least take more time, and perhaps a new generation of teachers, for corpora to find their way into the language classroom.

As part of this development, a number of methodological difficulties of corpus use in language pedagogy need to be overcome (Braun, 2005; Cook, 1998; Gavioli \& Aston, 2001; Kaltenböck \& Mehlmauer-Larcher, 2005; Mishan, 2004; Siepmann, 2006; Tribble, 1997; Widdowson, 2003). Some of these difficulties relate to corpora as a pedagogical resource. While corpora provide genuine and potentially rich and interesting materials, there is a fundamental discrepancy between their textual nature and the discoursal and communicative nature of language learning. Corpora merely contain textual records of discourse situations, and the (re)contextualisation of these records, which is crucial if anything is to be learned from them, can be difficult and requires pedagogical mediation (Widdowson, 2003:102). This is, however, further exacerbated by the fact that many of the widely accessible corpora were created as tools for linguistic research and not with pedagogical goals in mind, with the result that their content and design does not necessarily meet pedagogical needs.

Equally importantly, there are methodological challenges relating to the exploration of corpora. One simple aspect of this is that language learners are usually not expert corpus users. More fundamentally though, corpus linguistics is, in the first place, a method of linguistic description and, as Cook (1998:57) has argued in this connection, "the leap from linguistics to pedagogy [...] is far from straightforward".

An additional problem of corpus application in secondary education has to do with curricular requirements. Many language teachers agree that language learning should be based on a rich repertoire of materials, and this seems to make the use of corpora an attractive option. At the same time, however, any materials included in the school syllabus need to fit in with the overall language curriculum. In the light of the methodological problems outlined above, it seems only natural that curricular requirements together with the ensuing time constraints are perceived as an additional, practical problem hampering the integration of corpus use in the classroom (see also Tribble, 2000).

Against the backdrop of these methodological challenges, it can be argued that the (successful) integration of corpora into a school context hinges on at least two specific pedagogical requirements. The first of these relates to the corpora themselves. The need for pedagogically motivated corpus content is well reflected in the many initiatives in tertiary education to create small 'home-made' or 'ad-hoc' corpora which contain similar texts and are more coherent than traditional corpora (e.g. O’Sullivan \& 
Chambers, 2006; Ghadessy, Henry \& Roseberry, 2001; Tribble, 1997). Given the curricular requirements in the school context, one can argue that corpora for secondary education should not only be more coherent than traditional corpora; they should, as far as possible, also be complementary to school curricula, to facilitate both the contextualisation process and the practical problems of integration.

Another requirement concerns the pedagogical mediation of corpora. As suggested in Braun (2005), one way of achieving this is through the 'enrichment' of corpora with support materials such as corpus-based learning activities and exercises to support the construction of knowledge and provide learners with opportunities to practise and test their knowledge. To avoid reinventing the wheel, the learning activities and exercises should be made available together with the corpus. Furthermore, to support the contextualisation process, traditional non-linear methods of corpus exploitation should be combined with activities for text-based exploration (whole-text reading). This, in turn, calls for pedagogically motivated annotation and query options.

On the basis of these requirements, I developed a method for the design and exploitation of a pedagogically relevant corpus (Braun, 2005) and created a small experimental corpus - ELISA (English Language Interview Corpus as a SecondLanguage Application) - to exemplify this method. ELISA currently consists of 25 video-based narrative interviews with native speakers of English from different countries and different walks of life. The informants talk about their professional career and their countries' cultural and natural resources. All interviews follow a similar pattern and cover a similar range of topics, most of which are highly relevant for educational contexts. Furthermore, ELISA provides easy access to entire interviews (video clips and transcripts) and relies on query methods which do not require much corpus linguistic knowledge. The corpus was pedagogically enriched by ready-made wordlists and concordances, and a set of learning activities for selected interviews (for a more detailed description of the corpus, see Braun 2005, 2006, 2007). ${ }^{1}$ The ELISA corpus provided the basis for designing the empirical case study which is the subject of this paper.

\section{The case study}

The primary objective of the case study was to investigate the conditions and challenges of integrating corpus materials and corpus-based learning activities into secondary education. A related aim was to investigate the appropriateness of the chosen corpus design for pedagogical exploitation.

\subsection{Design of the study}

The study was conducted at the Otto-Hahn-Gymnasium, a secondary school in Ostfildern (Baden-Wuertemberg, Germany), in autumn 2005. The participants were 26 pupils of the 9th grade (age 14-15). English was their first foreign language, and they had had English classes since grade 5. Over a period of four weeks, all English classes

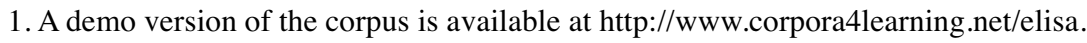


(four sessions per week) were taught by the author and a teacher trainee from the University of Tübingen. During this period, one unit of the students' textbook (English G 2000) was covered and complemented by materials from the ELISA corpus. The 4 -week period corresponded to the average time spent on each textbook unit in grade 9.

The textbook unit chosen as a basis for the study was a unit on Australia ('Australia Great Southern Land'). The ELISA corpus contains four interviews about Australia. Two of them focus on immigration, and the other two illustrate some of Australia's cultural heritage. Given the time constraints of the study, it was decided to use two of the 'Australian' interviews for a detailed text-based exploration and as a starting point for corpus-based learning activities. ${ }^{2}$ The design of these activities will be described in more detail in the following section; this section is intended to give an overview of what was done in the unit as a whole.

A crucial prerequisite for the permission to take over the class was to cover the main points of the textbook unit as far as possible, in spite of using the corpus materials. This was in line with the overall curricular issues outlined in section 1, meaning that the case study took place under very realistic conditions. The work with the corpus materials and the other work in the unit were integrated into a syllabus comprising the following five phases (Sander 2006):

1. Introduction to Australia, including materials from the textbook (photos, maps), a slide show and a discussion in class;

2. Use of the first ELISA interview (on immigration);

3. Work with materials from the textbook (short texts, dialogues, exercises) about Australia's past and present, including immigration and Australia's cultural heritage;

4. Use of the second ELISA interview (on Australia's cultural heritage);

5. Group presentations on individual aspects of Australia.

The two interviews were presented to the students in a similar way. They were first watched in class, using a data projector and a screen. This was followed by a discussion of the interview in class. It was only then that the interview was explored in detail, using computer-based activities (to support the process of building up knowledge) and exercises (to apply this knowledge), which had been created in the preparation of the study (see also section 2.2):

- To explore the first interview, all students worked through the same set of activities and completed the same set of exercises. Most of the activities were rather traditional, including explanations and awareness-raising tasks; a small

2. In the preparation of the study, corpus-based methods of analysis were used to support the selection of the two interviews. Thus, a wordlist of each interview was matched against a reference wordlist containing the words of all textbook units the students had covered from grade 5 to 8 , i.e. the theoretically 'known' vocabulary. This was further complemented by analyses of lexical density and average speech rate. 
set of activities was based on concordances and wordlists to help the students get used to corpus-based work on computer.

- To explore the second interview, the students were randomly assigned to one of two groups. One group worked though a set of traditional activities (henceforth the control group), while the other group was given corpus-based explorative activities (henceforth the corpus group). The exercises, however, were again identical for all.

This design follows Cobb's (1997:308) suggestion that it is more appropriate for a study of this type to have two groups working in the same environment, i.e. with different versions of computer-based activities, than to use e.g. computer-based and paper-based work, as "[t]he two versions form a minimal-pair set that allows controlled comparisons to emerge longitudinally". Whilst the study described here was not a longitudinal study, this design was nevertheless considered to be logistically efficient, and the results were expected to reveal at least tendencies with regard to learning success and students' attitudes towards the activities.

\subsection{The data base}

As pointed out in section 1, the overall data base of the case study was the ELISA corpus. The activities and exercises for the two selected interviews were created with Telos Language Partner (TLP), ${ }^{3}$ a template-based learning and authoring program for creating web-based learning materials (Kohn, forthcoming). TLP offers a wide range of

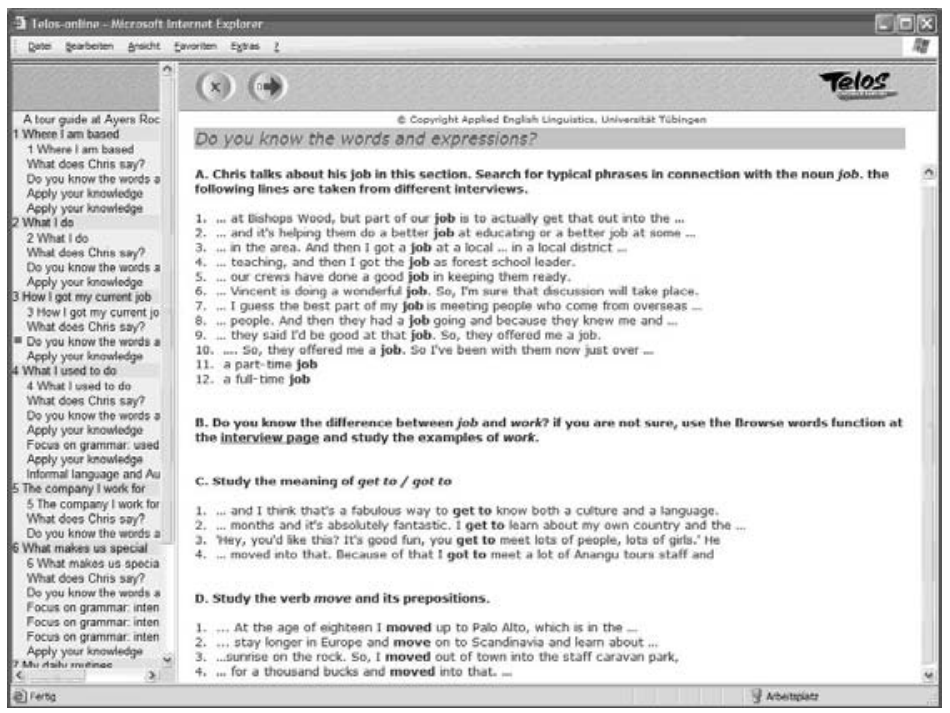

Fig.1. Corpus-based activities.

3. http://www.teloslearning.de 
multimedia templates (from templates for video exploration to text-based templates and cloze formats) and was thus well-suited to support the variety of activities that had been planned for the two interviews.

Each ELISA interview is divided into subsections based on the topics dealt with in the interview. This facilitates not only the exploration of the interviews but also the creation and allocation of learning activities and exercises. Thus, each interview section of the first interview was assigned one set of activities and one final exercise, and each section of the second interview was assigned two different sets of activities (traditional vs. corpus-based) and one final exercise, in accordance with the design of the study described in section 1.1.

By default, the first activity of each set was a video exploration activity in which the students had the opportunity to watch the relevant interview section again (after having watched the entire interview in class). The traditional activities following on from this characteristically consisted of explanations and examples or awareness-raising tasks such as gapped versions of the relevant section of the interview transcript. The corpusbased versions of the activities included activities originally suggested by Johns and King (1991), Tribble and Jones (1990) and others, and were typically based on the exploration and/or use of:

- $\quad$ ready-made frequency lists of each interview;

- $\quad$ selective concordances (see Figure 1, activities A, C and D), mainly consisting of concordance lines from the two interviews used in class but complemented, in some activities, by selected 'clear-cut' examples from other interviews;

- ready-made full concordances of each interview, offering a complete alphabetical wordlist of the interview and the option to click on any word to see a KWIC concordance of it (referred to as "browse word" function in Figure 1, activity B);

- the ELISA online concordancer, which provides extended search options (regular expressions, wild cards, search for phrases).

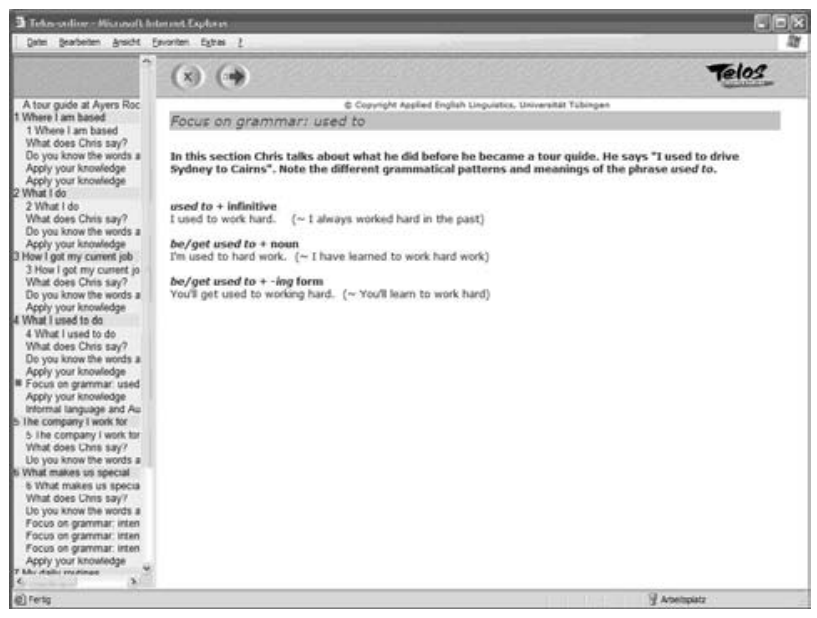

Fig. 2. Traditional version of a grammar activity. 
Most of the activities focused on lexical and grammatical points, because it was assumed that their exploration would be feasible for both groups, using different methods and examples. Furthermore the activities were designed to match lexical and/or grammatical points covered in the textbook unit. In one part of the textbook unit, for instance, the structure used to + INF was introduced. In accordance with the textbook's overall approach this was done by giving the main rule along with an example. Similar examples were therefore included in one traditional activity for the second interview (see Figure 2), whereas a corpusbased version of this activity was created for the corpus group (see Figure 3; the concordance lines are taken from the second interview as well as other interviews in the corpus).

However, apart from the many lexical and grammatical activities, relying on concordance and wordlists, a range of other tasks was also included. This was to avoid an overly tight focus on corpus linguistics and was in accordance with the overall aim to have the students explore the corpus materials from as many different angles and in as many different ways as possible. Evident types of activity for the ELISA corpus included the exploration of:

- different varieties of English, through listening to sections from interviews with speakers from different countries;

- colloquial expressions and other features of spoken English, through studying selected interview passages.

The exercises at the end of each section were designed to 'test' what the students had learned in the activities assigned to this section. They were, therefore, based on multiple-choice and drag-and-drop formats.

\subsection{Methodology}

To date very little is known about the use of corpus-based materials and learning

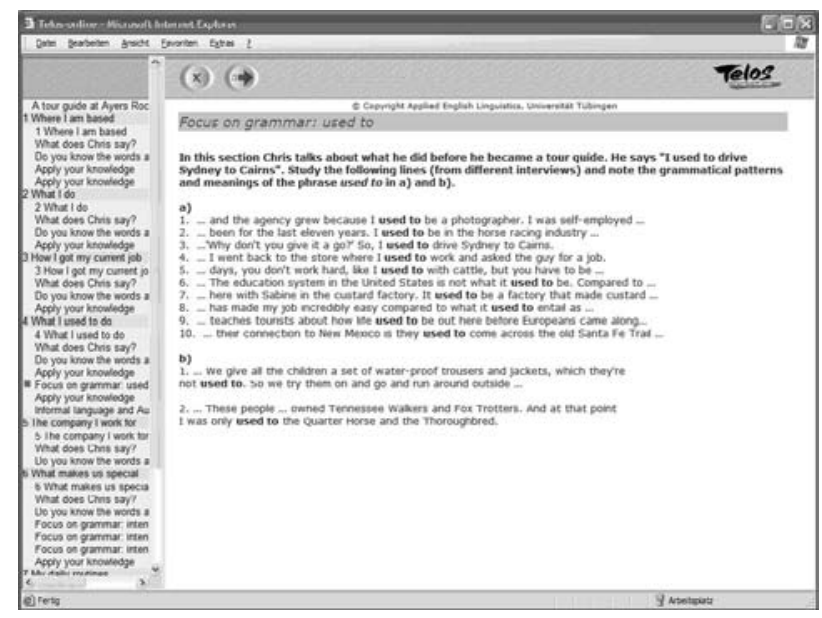

Fig. 3. Corpus-based version of a grammar activity. 
activities in secondary education. From a research perspective, the first step must, therefore, be to develop a comprehensive view of the overall conditions of corpus use in school, including the potential challenges involved. In other words, it would be extremely difficult to isolate and examine a limited number of variables in a controlled-experiment approach. Moreover, as was pointed out earlier, curricular requirements meant that, understandably, all major points of the textbook unit would be covered while - or in spite of - 'experimenting' with the corpus. This meant that the study had to take place in a real-life context rather than under 'laboratory' conditions.

In view of this situation, a case-study approach was deemed to be the most appropriate strategy, and relying on multiple sources of evidence, both qualitative and quantitative, was a priority. The study, therefore, combined the following types of data:

- $\quad$ Results from marking coursework carried out prior to using and/or independent of any of the corpus-based activities, including a photo description following the slide show and discussion about Australia, a written summary of the first interview after watching it in class as well as an intermediate vocabulary test;

- Results from the logs of the computer-based exercises and from a final, computer-based test. The e-Learning platform Moodle was used to this end, because it provides for user authentication and controlled access to learning materials and, equally importantly, because Telos Language Partner, the authoring software used to create the computer-based materials, 'communicates' with a Moodle database to $\log$ the results of the TLP exercises;

- Responses to a final questionnaire in which the students rated e.g. their perceived learning success and their personal preference for individual activities, using 5point Likert scales and free comments;

- Comments made by the students in the final discussion of the unit;

- Observations made by the author and the teacher trainee who team-taught the class during the study.

The results from coursework were used to assess the overall proficiency of each student and of the randomly assigned groups. Further evidence for this was gained from the logged exercises of the first interview (identical activities for all) and the final test. The logs of the second interview as well as the questionnaire data and the qualitative data (students' comments and observations) were analysed with the aim of assessing the overall success of integrating corpus material into the chosen learning unit, and in particular the usefulness and popularity of the corpus-based activities.

The coursework was marked using the German grading system, and the computer logs generated grades in percentage points. The results of the two groups were compared using a parametrical test (paired t-test for independent samples), since these data can be assumed to have a nominal distribution, i.e. the difference between adjacent points on the scale is equal. By contrast, the responses to the questionnaire (Likert scales) were treated as ordinal data, since it cannot be assumed that the respondents perceive the difference between adjacent points on the scale as equal (e.g. "very much" and "much" vs. "much" and "something"). In line with this assumption, responses from the two 
groups were compared using the Mann-Whitney U test, a non-parametrical test for independent samples; results from different tasks within one group were compared using the Wilcoxon signed-rank test, a non-parametrical test for repeated measurements on a single sample (for an overview of data analysis in the context of evaluating educational technology, see Harvey, 1998).

Given that data collected from Likert scales are ordinal rather than nominal, it is strictly speaking not logical to calculate mean scores of the responses; the median (the mid-point of the distribution of all responses) is more appropriate (see ibid.). However, since the aim of this study was to obtain tendencies and since mean scores are a very familiar measure, both mean and median values will be given in the results section where relevant.

With regard to the quantitative analysis of the data, it furthermore needs to be pointed out that no stark differences were to be expected between the corpus group and the control group for several reasons. Firstly, in both groups some learning was expected to take place. Secondly, the time span of the study was very short. Again, the aim of the quantitative analyses was to get some tendencies on the learning success and attitudes towards corpus-based materials.

\section{Findings}

\subsection{Background}

Of the 26 students in the class, the data of 25 students were taken into account. One student had missed a number of sessions, with the result that his work was incomplete and he was not considered to be able to evaluate all learning activities.

Because of the limited time frame which was available for an introduction to the computer-based activities and the corpus materials, it was assumed that the acceptance

Table 1 Results from marking student work (differences not significant according to paired $t$-test, $p \leq 0.05$ )

\begin{tabular}{|c|c|c|c|c|c|}
\hline & $\begin{array}{c}\text { All } \\
\text { students }\end{array}$ & $\begin{array}{c}\text { Tradit. Group } \\
\mathrm{n}=12\end{array}$ & $\begin{array}{c}\text { Corpus group } \\
\mathrm{n}=13\end{array}$ & $\mathrm{p} \leq 0.05$ \\
\hline $\begin{array}{c}\text { Photo } \\
\text { description }\end{array}$ & 2.55 & $\begin{array}{c}\text { Mean } \\
\text { SD }\end{array}$ & $\begin{array}{c}2.64 \\
0.778\end{array}$ & $\begin{array}{c}2.46 \\
0.723\end{array}$ & \\
\hline $\begin{array}{c}\text { Written } \\
\text { summary of Ist } \\
\text { interview (after } \\
\text { watching in class) }\end{array}$ & 2.65 & $\begin{array}{c}\text { Mean } \\
\text { SD }\end{array}$ & $\begin{array}{c}2.50 \\
0.947\end{array}$ & $\begin{array}{c}2.80 \\
0.954\end{array}$ & \\
\hline $\begin{array}{c}\text { Intermediate } \\
\text { vocabulary test }\end{array}$ & 2.83 & Mean & 2.77 & 2.89 & \\
\hline
\end{tabular}


of the materials and the perceived learning success would be influenced by the students' previous experience with genuine materials, their familiarity with computer-based work and their attitude towards using computers for (language) learning.

Sixty-five per cent of the students stated that they had "very much" or "much" experience in working with computers, and all students were familiar with using the web. Furthermore, many students had had "much" or "very much" experience with the use of language learning software (50\% for CD ROM and $31 \%$ for web-based programs). Observation of the students during the computer-based sessions confirmed that after the instructions provided at the beginning of the first computer session they were mostly at great ease handling the computer-based tasks. Forty per cent of the students stated that they had a "positive" or "very positive" attitude towards computerbased language learning.

Equally important, more than half of the students (53\%) stated that they at least "sometimes" watched films or TV in English, in their leisure time, and 46\% at least "sometimes" had contact with native speakers of English.

\subsection{Results from marked work and computer logs}

The students' coursework was marked to assess the overall proficiency level of the class and of each of the two groups. The results for these tasks are summarised in Table 1 ( $1=$ highest, $5=$ lowest). The differences between the groups are not significant.

Table 2 summarises the percentage points achieved in the computer-based work (from $0 \%$ to $100 \%$ ). As outlined in section 2.2, the two groups were given identical activities for the first interview and group-specific activities for the second interview, whilst the logged exercises for each interview and the final test were identical for all students. The corpus group performed slightly better in the logged exercises, and for the exercises of the second interview this difference is significant.

\subsection{Perceived learning success}

To complement the results from marking and logging, the students were asked to rate

Table 2 Results from logging computer-based work in per cent

(* difference significant according to paired t-test, $p \leq 0.05$ )

\begin{tabular}{|c|c|c|c|c|c|}
\hline & $\begin{array}{c}\text { All } \\
\text { students }\end{array}$ & $\begin{array}{c}\text { Tradit. Group } \\
\mathrm{n}=12\end{array}$ & $\begin{array}{c}\text { Corpus group } \\
\mathrm{n}=13\end{array}$ & $\mathrm{p} \leq 0.05$ \\
\hline First interview & 70.21 & $\begin{array}{c}\text { Mean } \\
\text { SD }\end{array}$ & $\begin{array}{l}66.50 \\
0.103\end{array}$ & $\begin{array}{l}73.92 \\
0.100\end{array}$ & \\
\hline Second & \multirow{2}{*}{70.17} & Mean & 67.33 & 73.00 & $*$ \\
interview & & SD & 0.060 & 0.042 & $*$ \\
\hline \multirow{2}{*}{ Final test } & \multirow{2}{*}{67.86} & Mean & 67.17 & 68.54 & \\
& & SD & 0.090 & 0.069 & \\
\hline
\end{tabular}


their perceived learning success for the entire unit as well as for individual activities on a 5-point Likert scale with (1) meaning "I did not learn anything" and (5) meaning "I learned very much".

Considering the unit as a whole, 14 out of the 25 students $(56 \%)$ thought that they had learned "very much" $(n=1)$ or "much" $(n=13)$. The distribution of all ratings is shown in Figure 4 - in percentages rather than student numbers because of the difference in the number of students per group. The mean score was 3.6; the median - indicating the central tendency - was 4 ("learned much").

A comparison of the two groups reveals that the control group rated the overall success slightly higher than the corpus group (mean scores 3.7 vs. 3.5 ; medians 4 vs. 3), but the difference is not significant.

With regard to the perceived usefulness of individual activities in the unit, only the rating for project work stands out (4.0), whereas all other activities shown in Figure 5

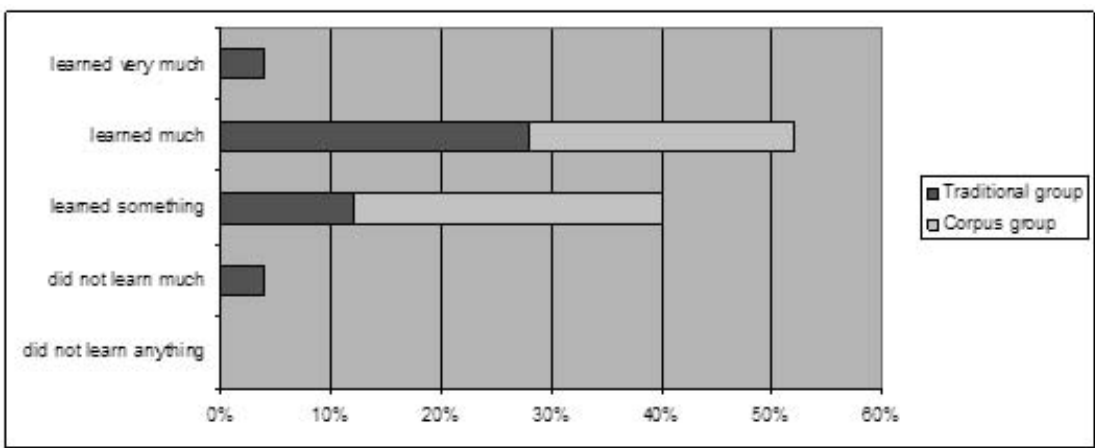

Fig. 4. Ratings of perceived learning success for the unit as a whole.

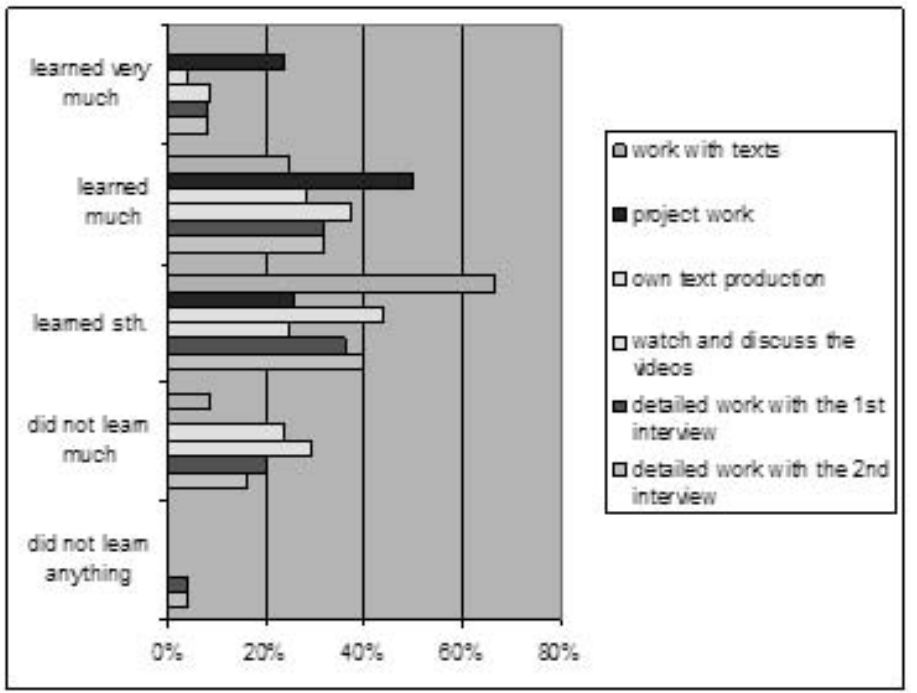

Fig 5. Ratings of perceived learning success for individual activities. 


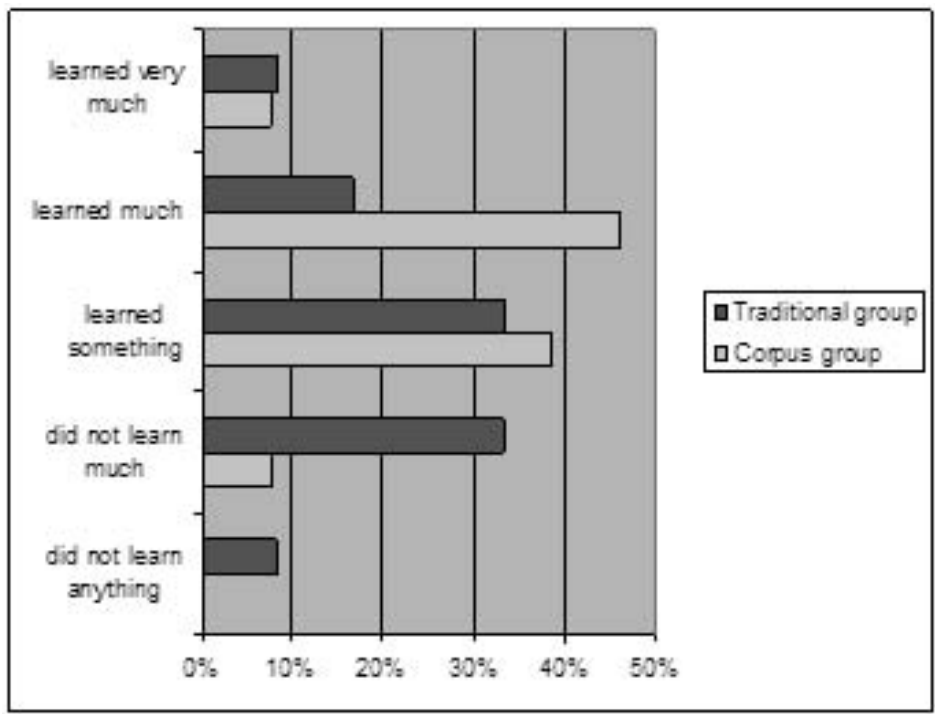

Fig. 6. Ratings of perceived learning success for the second interview (class divided).

Table 3 Ratings of perceived learning success and personal preference of the two interviews

(*significant difference according to Mann-Whitney $U$ test for independent samples, $p \leq 0.05$;

**significant difference according to Wilcoxon signed rank test for repeated measurements, $p \leq .05)_{\Lambda}$

\begin{tabular}{|c|c|c|c|c|c|c|}
\hline & & & $\begin{array}{c}\text { All } \\
\text { students }\end{array}$ & $\begin{array}{l}\text { Tradit. } \\
\text { Group }\end{array}$ & $\begin{array}{l}\text { Corpus } \\
\text { group }\end{array}$ & $\begin{array}{c}\text { Comparison } \\
\text { between } \\
\text { groups } \\
\mathrm{p} \leq 0.05\end{array}$ \\
\hline \multirow[t]{2}{*}{$\begin{array}{l}\text { Perceived } \\
\text { learning } \\
\text { success }\end{array}$} & $\begin{array}{c}\text { First } \\
\text { interview } \\
\text { Second } \\
\text { interview }\end{array}$ & $\begin{array}{l}\text { Mean } \\
\text { Median } \\
\text { Mean } \\
\text { Median }\end{array}$ & $\begin{array}{c}3.2 \\
3 \\
3.2 \\
3\end{array}$ & $\begin{array}{c}3.0 \\
3 \\
2.8 \\
3\end{array}$ & $\begin{array}{c}3.5 \\
3 \\
\\
3.5 \\
4\end{array}$ & $*$ \\
\hline & \multicolumn{4}{|c|}{$\begin{array}{l}\text { comparison across } \\
\text { Interviews } p \leq 0.05\end{array}$} & \multicolumn{2}{|l|}{$* *$} \\
\hline $\begin{array}{l}\text { Personal } \\
\text { preference }\end{array}$ & $\begin{array}{c}\text { First } \\
\text { interview } \\
\text { Second } \\
\text { interview }\end{array}$ & $\begin{array}{l}\text { Mean } \\
\text { Median } \\
\text { Mean } \\
\text { Median }\end{array}$ & $\begin{array}{c}3.4 \\
3 \\
3.5 \\
3\end{array}$ & $\begin{array}{c}3.0 \\
3 \\
3.0 \\
3\end{array}$ & $\begin{array}{c}3.8 \\
4 \\
\\
4.0 \\
4\end{array}$ & $\begin{array}{l}* \\
*\end{array}$ \\
\hline & $\begin{array}{l}\text { nparison } \\
\text { erviews }\end{array}$ & & & & & \\
\hline
\end{tabular}


received mean scores between 3.1 and 3.3. This indicates that with the exception of project work, there was not much difference between the perceived learning success from the more familiar textbook-based activities (work with texts, own text production) and the novel computer/corpus-based activities (the detailed work with the interviews). However, the dispersion of ratings suggests that the students were more heterogeneous in their ratings of the novel activities.

An interesting picture emerges when comparing the ratings for individual activities across the two groups. While there were no significant differences between the groups in any of the ratings of the (more familiar) textbook-based activities in the unit, the inter-group ratings for both interviews turned out to differ significantly. In contrast to the ratings of the perceived learning success for the unit as a whole, however, it was the corpus group who assigned the higher scores here.

The mean response of the control group was 3.0 and 2.8 for the first and second interview respectively; the median was 3 for both interviews. The corpus group's mean score was 3.5 for both interviews (median 3 and 4 for the first and second interview respectively). The median of 4 indicates that more than half of the corpus group thought that they had learned "very much" or "much" from the activities related to the second interview. The distribution of the groups' ratings for the second interview is shown in Figure 6. A summary of the ratings, mean scores and median values is given in Table 3.

With regard to the perceived learning success, there is thus an interesting inter-group discrepancy between overall success (rated slightly higher by the control group) and interview-related success (rated significantly higher by the corpus group). However, the perceptions about the interviews were in line with the actual performance as obtained from the computer logs (corpus group better in both interviews, see Table 2).

\subsection{Personal preference}

The results in relation to the perceived learning success were also matched by students' responses to the question about how much they liked the individual activities. The students were asked to rate their personal preference on a 5-point Likert scale ranging from (1) did not like it at all to (5) liked it very much. The mean response of the control group to this question was 3.0 for both interviews, and the median was 3 in both cases. The corpus group rated the first interview at 3.8 (median 3) and the second at 4.0 (median 4). All results are summarised in Table 3; the distribution of responses for the second interview is shown in Figure 7. As in the category "perceived learning success", the inter-group difference is again significant for both interviews.

One further interesting result emerges from the ratings of both personal preference and perceived learning success. The corpus group's rating of the perceived learning success for the second interview (see Table 3 ) is not only higher than the control group's rating for the same interview, but it is also higher than the corpus group's rating of the first interview, and this difference is also significant. By contrast, the corpus group's ratings of their personal preferences for the two interviews do not differ significantly. There are no such differences in the ratings of the control group. This suggests that irrespective of their personal preferences, the students in the corpus group found the (corpus-based) activities with which they worked in the second interview more useful 


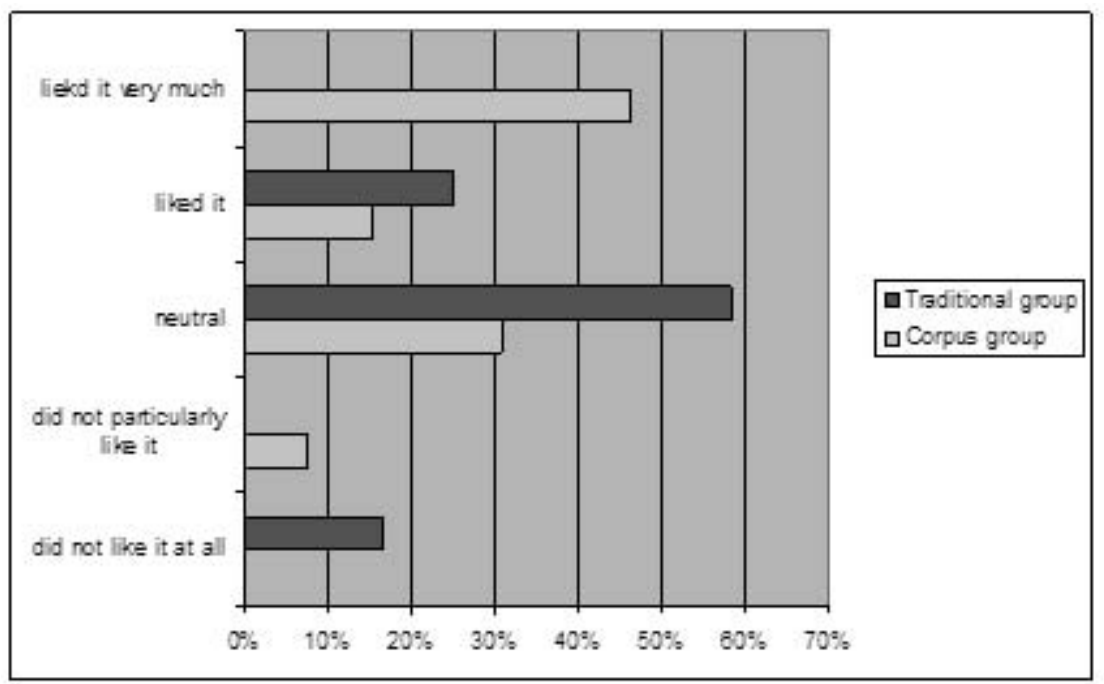

Fig. 7. Ratings of personal preference for the second interview (class divided).

than the (traditional computer-based) activities they carried out in connection with the first interview.

The clear distinction the students made between their personal preferences and the perceived learning success certainly adds further credibility to the latter. The distinction is also corroborated by the students' qualitative comments in the questionnaire and in the final discussion. While many generally welcomed the work with the interviews (e.g. "I liked the videos with English native speakers; you could see how much you would understand in reality"), some indicated that they made a clear difference between the two categories (e.g. "I did not particularly like the videos, but I have learned quite a lot from them"; "The accounts of people's lives were very interesting, but they could have been shorter".

\subsection{Knowledge and skills}

What is furthermore revealing is the rating of the perceived improvement of knowledge and skills. Asked to rate the perceived improvement on a 5-point Likert scale ranging from (1) "I did not learn anything" to (5) "I learned very much", a large majority of students $(85 \%)$ thought that they had learned "very much" or "much" about Australia, and more than one third believed to have improved "very much" or "much" with regard to their listening comprehension skills (36\%), speaking skills (36\%) and knowledge of vocabulary $(35 \%)$. By contrast, only $16 \%$ believed that they had learned "very much" or "much" about grammar.

In connection with this, the qualitative comments made by the students in the questionnaire and in the final discussion provide useful insights. One student commented: "I did not learn much grammar. We did not write down any rules". This view was generally echoed by a number of other students in the final discussion and will be discussed further in section 4.2. 


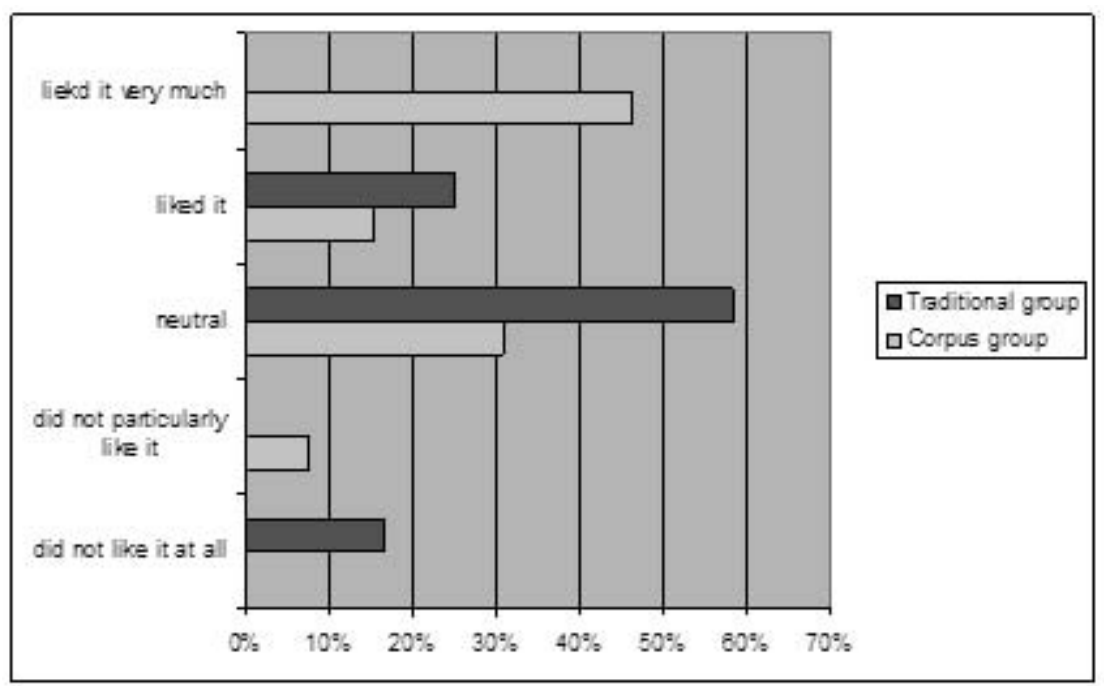

Fig. 8. Ratings of perceived learning success in the area of grammar.

There are, however, once again interesting differences in the distribution of the grammar ratings across the two groups. While the difference fails to reach significance here, it is noteworthy that four of the thirteen students in the corpus group thought that they had learned "very much" or "much" about grammar, whereas none of the students in the control group chose either of these ratings. Figure 8 provides further details about the grammar ratings.

In spite of the higher ratings given by the students of the corpus group, Figure 8 also shows that they were much less uniform in their perceptions. This raises, of course, a whole range of questions about the effectiveness of the various activities in supporting the construction of grammatical knowledge.

When assessing the students' responses we must, however, also bear in mind that there were a number of interferences. Some of the qualitative comments, for example, pointed to concerns about covering everything in the textbook unit, with the result that the 'additional', corpus materials were considered (by some) to be distracting. A very different interference reveals itself in the following comment about one of the sessions in which the students worked with the second interview. One student stated: "In this session I was thinking of the Latin test we were going to write on that day". Observation of the students during this session made it clear that some of them made a 'last-minute'attempt to boost their Latin vocabulary, which partially distracted them from the interview-related activities.

\section{Discussion}

\subsection{General observations}

The data relating to those activities for which the class was not divided indicate that the two groups did not differ significantly with regard to their overall 
proficiency. By contrast, the corpus group scored significantly better in the computer-based exercises for the second interview. This finding was matched by the corpus group's higher ratings of the perceived learning success for the second interview, both in comparison with this group's rating of the first interview and in comparison with the control group's rating of the second interview. At first sight then, the data seem to suggest that the corpus-based activities were more effective and were perceived to be more useful than the more traditional computer-based activities. This is in line with results of empirical research into corpus-based learning in tertiary education. In particular, Cobb (1997) successfully used computer-based concordance exercises to increase lexical proficiency in tertiary education, replicating earlier results by Stevens (1991) on the effectiveness of paper-based concordance-based exercises.

However, given the case-study approach adopted in this study and bearing in mind the restrictions of the study, the significance of the quantitative results should not be overestimated. There are other indicators that point to a more diversified picture and deserve discussion.

Firstly, there is of course the point that the corpus group rated both interviews more favourably in terms of perceived learning success and personal preference than the control group (see Table 3), even though the activities in the first interview were identical for both groups. It could be argued that the more positive evaluation of the first interview by the corpus group was due to a knock-on effect of their more positive (retrospective) perception of the second interview.

Secondly and perhaps more importantly, there was neither a significant difference between the groups' ratings of perceived learning success for the unit as a whole nor for the final test. In other words, the inclusion of a set of corpus-based activities did not immediately lead to a perceived or real improvement in the proficiency of the corpus group. Given the short time devoted to corpus-based activities this may not come as a surprise. Moreover, as was pointed out earlier, it was to be expected that some learning would occur in both groups, which made any strong differences between the groups unlikely.

However, one final point is interesting in connection with this. The (novel) interview-related activities and most of the more familiar activities in the unit were given equally high ratings for perceived learning success. Bearing in mind that the interview-related activities and in particular the corpus-based activities presented the students with a number of difficulties and that there was not much time to get used to them, this can be interpreted as a positive result. It points to a general ability on the part of the students to adapt to the new activities. The greater dispersion of the responses for these in comparison to the responses for the more familiar activities (see Figure 5), however, indicates that the students varied with regard to this, revealing differences in their level of independence or autonomy. This point will be examined further in the next section.

\subsection{Corpus-based learning activities}

One noteworthy point with regard to skills and knowledge is that the ratings for the perceived improvement of lexical knowledge were not outstanding despite the strong 
focus on this in the computer-based activities, and ratings for grammar were even lower. The students' comments on the unit provide important clues for an explanation of this assessment. In the context of this study, statements such as "I did not learn much grammar. We did not write down any rules". may point to 'strategic' considerations: the students were on the whole eager to learn and were keen to cover all points of the textbook unit to ensure that they would not encounter any problems in subsequent units and, understandably, that they would score well in subsequent tests. More importantly, however, such statements reflect prevailing perceptions about learning: it is still seen as something that happens only if, or as soon as, something is being written down.

A related but different point concerns the inductive and analytical skills required for the exploration and interpretation of corpus data. The students' main problem was not that they were not able to explore linguistic data and discover interesting points in them. Moreover, they were certainly able to adapt to the novel activity formats (see section 4.1). The major problem the students faced in the corpus-based activities was that the interpretation of wordlists and concordances (whether comprehensive or selective) requires a level of analytical skill and attention to detail which they had simply not yet acquired. This became clear in discussing the corpus-based exercises with the students on an individual basis during the computer-based sessions.

Since great care was taken in the preparation of the activities to ensure that they matched the students' level of proficiency (see section 2.3), it would appear that the students' problems in analysing the concordances and wordlists and learning something from this type of data had to do with to a lack of appropriate strategic (procedural) knowledge and skills - and a lack of autonomy - rather than a lack of linguistic (declarative) knowledge, although the precise relationship between the two in the exploration of corpus data would be an interesting point to explore.

According to cognitive-constructivist learning theories, learning can only take place by constructing knowledge in the mind from appropriate learning activities and materials. Clearly, this construction process involves exploration, interpretation and autonomy. The discrepancy between the students' mastery of these skills and the indispensable construction of knowledge in the process of learning raises interesting questions with regard to the appropriateness of the corpus-based activities and corpuslinguistic methods in the school context in general.

This is related to Widdowson's point that the use of genuine materials in a learning context, especially corpus-based materials such as concordances, does not guarantee that they can be contextualised by the students (see section 1). More importantly in the context of the present discussion, this also relates to the types of activities which are appropriate to foster exploration and interpretation, contextualisation and construction of knowledge. Kohn's (2006:288) distinction between 'low-level construction' and 'high-level construction' activities is useful here. By the former he refers to activity and exercise formats which have often been stigmatised in communicative and constructivist approaches to language pedagogy as being 'instructivist'. In the simplest case this would be e.g. cloze exercises and similar form-focussed activities. Kohn claims that learning (or construction) takes place in both or indeed all types of activities ${ }^{4}$

4. Kohn, therefore, carefully distinguishes between constructivist theories about learning 
and that 'low-level construction' activities can be highly appropriate, depending on how they are embedded in the overall learning context and on the level of the learner's knowledge and autonomy. 'Low-level' construction activities can usefully prepare the ground for 'high-level' construction activities.

Apart from this, the use of any type of computer-based activities in the school context also creates some logistical challenges which should not be neglected. Despite efforts in many schools, including the Otto-Hahn-Gymnasium, to make things more flexible, the rhythm at school is still governed by the hourly slots and the breaks in between, in which students 'switch' e.g. from Mathematics to English to Latin. This means not only that activities have to be timed and - when involving computer rooms - timetabled accordingly, but also that students may be preoccupied with another lesson (such as a test in Latin) or simply be overwhelmed with the amount of information they are expected to digest every day. All this puts further constraints on the scope for exploration and the development of autonomy.

\subsection{Revision of requirements for corpus integration}

One might be tempted to conclude then that the use of corpus-based activity formats is simply of limited use and success in secondary education. Kaltenböck and MehlmauerLarcher (2005:80-81), for example, cautiously conclude:

[W] hen using corpora for language learning a cautious approach seems advisable in order to avoid excessive demands, which can lead to frustration on the part of the learners. The learners' age, their general level of language competence, levels of expert knowledge and the learners' attitude towards increasing their learner autonomy all have to be taken into consideration when deciding on how corpora can be used in a foreign language learning context. Realistically speaking, it is therefore questionable whether - as predicated by Sinclair (1997: 30) - even "[q]uite young learners will gain access to this [= the corpus] and will become self-taught DDL (data-driven learning) students".

In the light of the case study outlined in this paper, Sinclair's vision of learners becoming "researchers" seems indeed slightly problematic in the context of secondary education.

On the basis of all the data gathered from the case study, however, a more fruitful conclusion also seems to emerge. In order to turn corpora into a more effective and attractive resource for a wider range of users, and in particular for 'non-expert' users in the secondary school context, teachers and materials designers may have to move away from, or beyond, 'classic' concordance-based activities and think of other tasks to foster exploration, knowledge construction and eventually the development of greater autonomy through the use of corpus materials. Multimedia corpora, especially, open up a plethora of new opportunities here (see also Braun, 2006). These do not need to be spoken corpora. McEnery and Wilson (1997b) and Mishan

(learning as construction of knowledge) and constructivist approaches to learning (which learning activities are best suited to supporting the construction process). 
(2004), for example, have made suggestions on how written corpora can be supplemented with other-media materials in order to increase their potential for educational contexts.

As a consequence, the requirements for using corpora in school contexts (see section 1), could be revised in the following ways. Firstly, it is not enough to reflect upon the integration of corpora as such into the curriculum. Integration needs to be defined more precisely. It concerns both the corpus content (ensuring appropriateness and complementarity) and the ways in which the corpus is explored and exploited. Apart from general pedagogical considerations of e.g. learning styles, preferences, attention span and hence variation of methods, there is a specific need for carefully combining 'classic' corpus-linguistic methods ('high-level exploration') with other methods ('lower-level exploration'). Secondly therefore, the integration of corpus work entails a methodological challenge which can hardly be underestimated in the school context and which must play a vital role in teacher training. The major objective for the future generation of language teachers is not to become corpus linguists; it is certainly to understand the huge potential of corpora for language pedagogy, but then to master the methodological challenge of their integration.

To do this, teachers will need support from corpus designers, and the task for them is to build on the pedagogical requirements for the use of corpora. This also calls for support tools which are tailored to pedagogical needs of corpus creation. The Socrates project SACODEYL, for example, which aims to create spoken youth language corpora for pedagogical purposes in seven European languages, has adopted an approach of basing the corpora on subject areas outlined in the Common European Framework to ensure that the corpus contents are relevant for pedagogical contexts. Furthermore, the project is concerned with the development of pedagogically relevant tools to support the creation and the pedagogical (as opposed to the linguistic) exploitation of these corpora. 5

\section{Conclusion}

This paper has reported on an empirical case study conducted to investigate the integration of corpora and corpus-based activities into a learning unit at secondary school level. It was hypothesised that the integration of corpora into secondary education has to meet with a number of specifically pedagogic requirements concerning the complementarity of corpus and curriculum content, the accessibility of the corpus for non-expert users and the mediation of the corpus in the pedagogical context. The overall positive results emerging from the study create optimism especially with regard to the students' interest in, and adaptability to, genuine corpus

5. The SACODEYL project (System-Aided Compilation and Open Distribution of European Youth Language) is funded under the Minerva action "Promotion of open and distance learning" in the EU Socrates programme from 2005-2008 (Ref: 225836-CP-1-2005-1-ESMINERVA-M co-ordinator: University of Murcia, Spain). The developers of the ELISA corpus (at the Universities of Tübingen and Surrey) are partners in this project. 
materials. At the same time, the results point to a number of challenges when it comes to the detailed exploration of the materials. The problems which have been identified range from skills-related problems to methodological and logistical points. Their resolution may not be as difficult as squaring a circle, but much more effort is certainly required with regard to developing a methodological 'masterplan' for corpus integration into secondary education. On the one hand, this concerns the design of the corpora themselves and of relevant activities for their exploration. On the other hand, it also calls for teacher training and perhaps a better understanding of the pedagogical (as opposed to the linguistic) needs of corpus analysis. All in all, it is time for a move from data-driven learning to needs-driven corpora, activities and methodologies.

\section{Acknowledgements}

The author wishes to express her sincere thanks to her co-worker and teacher trainee Steffi Sander, to the staff of the Otto-Hahn-Gymnasium in Ostfildern, who agreed to host this study and provided generous support throughout all phases of it, to the students who took part in this study, and to Kurt Kohn for a discussion of an earlier version of this paper.

\section{References}

Amador Moreno, C., Chambers, A. and O'Riordan, S. (2006) Integrating a corpus of classroom discourse in language teacher education: the case of discourse markers. ReCALL, 18(1): 83-104.

Braun, S. (2005) From pedagogically relevant corpora to authentic language learning contents. ReCALL, 17(1), 47-64.

Braun, S. (2006) ELISA - a pedagogically enriched corpus for language learning purposes. In: Braun, S., Kohn, K. and Mukherjee, J. (eds.), Corpus Technology and Language Pedagogy: New Resources, New Tools, New Methods. Frankfurt/M: Peter Lang, 25-47.

Braun, S. (2007) Designing and exploiting small multimedia corpora for autonomous learning and teaching. In: Hidalgo, E., Quereda, L. and Santana, J. (eds.) Corpora in the Foreign Language Classroom. Selected papers from TaLC 2004. Amsterdam: Rodopi, 31-46.

Braun, S. and Chambers, A. (2006) Elektronische Korpora als Resource für den Fremdsprachenunterricht. In: Jung, U. (ed.) Praktische Handreichung für Fremdsprachenlehrer. Frankfurt/M.: Peter Lang, 330-337.

Chambers, A. (2007) Popularising corpus consultation by language learners and teachers. In: Hidalgo, E., Quereda, L. and Santana, J. (eds.) op. cit., 3-16.

Cobb, T. (1997) Is there any measurable learning from hands-on concordancing? System, 25 (3): 301-315.

Cook, G. (1998) The uses of reality: a reply to Ronald Carter. ELT Journal, 52 (1), 57-63.

Davies, B. and Russell-Pinson, L. (2004) Concordancing and corpora for K-12 teachers: project MORE. In: Connor, U. and Upton, T. (eds.) Applied Corpus Linguistics: a multidimensional perspective. Amsterdam: Rodopi, 147-169.

English G 2000 (2002) Schülerbuch für das 9. Schuljahr an Gymnasien. Berlin: Cornelsen.

Gavioli, L. and Aston, G. (2001) Enriching reality: language corpora in language pedagogy. ELT 
Journal, 55 (3): 238-246.

Ghadessy, M., Henry, A. and Roseberry, R. (eds.) (2001) Small Corpus studies and ELT: theory and practice. Amsterdam: Benjamins.

Harvey, J. (ed.) (1998) Evaluation cookbook. Edinburgh: Learning Technology Dissemination Initiative of the Institute for Computer Based Learning, Heriot-Watt University. http://www. icbl.hw.ac.uk/ltdi/cookbook/cookbook.pdf.

ICT4LT website: http://www.ict4lt.org

Johns, T. (1986) Microconcord: a language-learner's research tool. System, 14(2): 151-162.

Johns, T. (1991) Should you be persuaded - two samples of data-driven learning materials. In: Johns, T. and King, P. (eds.) Classroom concordancing. Birmingham University: English Language Research Journal, 4: 1-16.

Kaltenböck, G. and Mehlmauer-Larcher, B. (2005) Computer corpora and the language classroom: on the potential and limitations of computer corpora in language teaching. ReCALL, 17 (1), 65-84.

Kohn, K. (2006) Blended Language Learning: Potential und Herausforderung. In: Jung, U. (ed.), op. cit., 286-292.

Kohn, K (forthcoming): Telos Language Partner: 'Do It Yourself' Authoring for Content-Based Language Learning. In: Gimeno, A. (ed.) Proceedings of the first Valencian workshop on computer-assisted language learning: Authoring tools for web-based call, Valencia: Universidad Politécnica de Valencia, 2007.

McEnery, T. and Wilson, A. (1997a) Teaching and language corpora. ReCALL, 9 (1): 5-14.

McEnery, T. and Wilson, A. (1997b) Multi-media corpora. In: Lewandowska-Tomaszczyk, B. and Melia, P. (eds.) PALC'97: practical applications in language corpora. Lodz: Lodz University Press, 24-33.

Mishan, F. (2004) Authenticating corpora for language learning: a problem and its solution. ELT Journal, 58 (3): 219-227.

Mukherjee, J. (2002) Korpuslinguistik und Englischunterricht: Eine Einführung. Frankfurt/M: Lang.

Mukherjee, J. (2004) Bridging the gap between applied corpus linguistics and the reality of English language teaching in Germany. In: Connor, U. and Upton, T. (eds.) op. cit., 239-250.

O'Sullivan, Í. and Chambers, A. (2006) Learners' writing skills in French: corpus consultation and learner evaluation. Journal of Second Language Writing, 15 (1): 49-68.

Rohrbach, J. (2003) 'Don't miss out on Göttingen's nightlife': Genreproduktion im Englischunterricht. Praxis des Neusprachlichen Unterrichts, 50: 381-389.

Sander, S. (2006) Korpusbasierte Lernmethoden und Modelle - eine Fallstudie. Unpublished Diploma Thesis, University of Tübingen.

Siepmann, D. (2006) Korpuslinguistik und Fremdsprachenunterricht. In: Jung, U. (ed.) op. cit., 321-330.

Sinclair, J. (1997) Corpus evidence in language description. In: Wichmann, A., Fligelstone, S., McEnery, T. and Knowles G. (eds.) Teaching and Language Corpora. London: Longman, 27-39.

Stevens, V. (1991) Concordance-based vocabulary exercises: A viable alternative to gap-fillers. In: Johns, T. and King, P. (eds.), op. cit., 47-63.

Tribble, C. (1997) Improvising corpora for ELT: quick-and-dirty ways of developing corpora for language teaching. In: Lewandowska-Tomaszczyk, B. and Melia, P. (eds.) op. cit., 106-117.

Tribble, C. (2000) Practical uses for language corpora in ELT. In: Brett, P. and Motteram, G. (eds.) A special interest in computers: learning and teaching with information and com-munic-ations technologies. Whitstable, Kent: IATEFL, 31-41. 
Tribble, C. and Jones, G. (1990) Concordances in the classroom: a resource book for teachers. London: Longman.

Widdowson, H. G. (2003) Defining issues in English language teaching. Oxford: OUP.

Wüsthoff, G. and Rüschoff, B. (2000) Working with words: concordancing. In: Kallenbach, C. and Ritter, M. (eds.) Computerideen für den Englischunterricht. Berlin: Cornelsen. 